\title{
Scoop de 2013: L'OMC devient pro-bien-être animal!
}

\author{
Sabine Brels ${ }^{1}$
}

Incroyable mais vrai: I'OMC s'est prononcé, le 25 novembre 2013, en faveur de la protection du bien-être animal! Même si le règlement de I'UE de 2009 interdisant les produits du phoque, constitue plusieurs violations au règles du commerce international ${ }^{2}$, la chasse aux phoques a été condamné comme une pratique cruelle, quelques soient les méthodes utilisées ${ }^{3}$ ! Qu'il s'agisse des chasseurs commerciaux du Canada comme de Norvège, ou des Inuits au Canada et au Groenland, les droits de chasse de ces communautés ne font aucune différence quant à la cruauté reportée dans les rapports scientifiques ${ }^{4}$.

Pour l'avenir de la protection animale, l'élément le plus porteur de cette décision est l'assertion selon laquelle les préoccupations liées au bien-être des animaux constituent "une valeur ou un intérêt important" ${ }^{5}$. En ce sens, la confirmation tant attendue par les juristes animaliers est enfin arrivée: le bien-être animal est un objectif relevant de la protection de moralité publique sous l'article XX a) du GATT ${ }^{6}$. De plus, il est reconnu que la protection du bien-être animal constitue un "objectif légitime" pour faire obstacle aux règles du commerce international, selon les conditions de l'article 2.2 de l'accord OTC'.

En ce sens, cette décision est une vraie "bombe"! En effet, le véritable "scoop" est enfin arrivé! Ce qui semblait, aux yeux des moins optimistes, irréaliste voire impossible, s'est pourtant produit. Mieux encore: bien que considérée comme nécessaire en vue de protéger le bien-être animal, la mesure de I'UE sur les produits du phoque a été remise en cause quant à ses incohérences non-protectrices ${ }^{8}$. En effet, I'OMC a décidé que cet objectif ne peut souffrir d'exceptions quand la cruauté des méthodes est avérée.

\footnotetext{
1 Doctorante en droit à l'Université Laval (Québec, Canada), spécialisée sur la protection animale en droit international et comparé

${ }^{2}$ L'OMC demande la mise en conformité pour violation des articles I:1 et III:4 du GATT et de l'article 2.1 de l'Accord OTC.

${ }^{3}$ Communautés européennes-Mesures prohibant l'importation et la commercialisation de produits dérivés du phoque, Rapports du groupe spécial, OMC, WT/DS400/R-WT/DS401/R, 25.11.2013. Notons que cette décision fait 212 pages dans sa version française.

${ }^{4} I d ., \S 7.224$ et 7.247 .

${ }^{5} I d ., \S 7.632$.

${ }^{6} I d ., \S 7.639$.

${ }^{7} I d ., \S 7.505$.

${ }^{8}$ Sur ces incohérences, voir l'article antérieur à la décision: S.BRELS, "Chasse aux phoques à l'OMC: Bien être animal et moralité publique en débat", Derecho animal, juin 2013: http://www.derechoanimal.info/images/pdf/SBrels-Chasse-aux-phoques-fra.pdf.
} 
Ainsi, la mesure de I'UE a été doublement invalidée pour la double exception prévue à l'interdiction:

-Premièrement, I'UE a fait preuve de "discrimination arbitraire", en autorisant uniquement les produits issus de la chasse des Inuits, afin de préserver les droits des autochtones face au bien-être des phoques ${ }^{9}$.

-Deuxièmement, elle a fait preuve de "protectionnisme déguisé", en autorisant les produits du phoque issus de la gestion des ressources marines dans ses états membres, aussi contraire à la protection visé $e^{10}$.

Souvent accusée d'aller contre les intérêts environnementaux comme ceux des animaux, en ne servant que les intérêts du commerce international, I'OMC a ainsi opéré un réel revirement de situation depuis le début des années 2000'. Cette évolution a commencé en 2001, lorsque l'organe d'appel de I'OMC a décidé que la protection des tortues marines menacées d'extinction pouvait permettre de faire obstacle au commerce international ${ }^{11}$. Cette décision fut prise en vertu de l'exception de l'article XX g) du GATT ${ }^{12}$, visant la préservation des ressources naturelles épuisables. Désormais, I'OMC va plus loin dans sa prise de position. Elle considère la protection du bien-être animal, non seulement comme un objectif légitime, mais comme un intérêt important. En rupture nette avec les précédentes décisions "anti-animalistes", cette décision ouvre une grande porte à la possibilité de protéger le bien-être animal par le recours aux restrictions commerciales, tant que celles-ci restent cohérentes et répondent pleinement à leur objectif.

Enfin, notons que cette décision vient confirmer le mouvement international amorcé ces dernières années en faveur de la protection du bien-être animal. Celui-ci sera amené à s'amplifier. Il est même possible de présager que, dans les années à venir, le droit international ne pourra plus faire sans tenir compte de cette préoccupation mondiale, de paire avec d'autres, comme la protection environnementale.

\footnotetext{
${ }^{9}$ Id., p.7. Préférence justifiée notamment à travers la Déclaration des Nations Unies sur les droits des peuples autochtones de 2007.

${ }^{10} I d$., p. 3-5 et 10. Ces pays concernent notamment la Suède et Finlande, lesquels pourraient subvenir seuls à la demande de l'UE.

${ }^{11}$ Voir la décision dite "Crevettes-Tortues II" de 2001 (WT/DS58/AB/RW, 22 Oct. 2001).

${ }^{12}$ Accord général sur les tarifs douaniers et le commerce (GATT):

http://www.wto.org/french/docs_f/legal_f/gatt47.pdf.
} 